American Journal of Biochemistry and Biotechnology 6 (2): 103-110, 2010

ISSN 1553-3468

(C) 2010 Science Publications

\title{
Endothelial Dysfunction Induced by Type 2 Diabetes Mellitus and Fibrinolytic Activity
}

\author{
Hussein F. Sakr \\ Department of Physiology, College of Medicine, King Khalid University, Abha 64121, Saudi Arabia
}

\begin{abstract}
Problem statement: Type 2 diabetes mellitus is the world's largest systemic and metabolic disease. Endothelin (ET) was first described as a peptidergic endothelium-derived constricting factor. Endothelin-1 is one of the endothelial factors that is overexpressed in cases of endothelial dysfunction. The fibrinolytic system is present in plasma with the degradation of fibrin polymers in blood clots. It is a proteolytic mechanism that results in the formation of one main enzyme, plasmin, which cleaves fibrin. Approach: A total of 20 normal white albino rats weighing between 180-200 g were used and divided into two groups each of 10 rats, one group served as a control which fed on normal chow diet, while the second group fed on high fat diet for one month, then received streptozocin $\left(25 \mathrm{mg} \mathrm{kg}^{-1}\right)$ intraperitoneally as a single dose and continued feeding on high fat diet. Plasma was separated to determine the levels of tissue Plasminogen Activator (t-PA), Plasminogen Activator Inhibitor-1 (PAI-1), Fibrin Degradation Products (FDPs) and Euglobulin Clot Lysis Time (ECLT). Results: Data showed that diabetic rats have inhibited fibrinolytic activity as detected from the significant increase in PAI-1, significant decrease in both t-PA and TDPs with significant prolongation of the ECLT relative to the control group. Conclusion: Endothelial dysfunction is associated with a prothrombotic state.
\end{abstract}

Key words: Type 2 diabetes mellitus, endothelin-1, endothelial dysfunction, fibrinolysis

\section{INTRODUCTION}

A balance between blood clot development and blood clot lysis is important for maintaining the integrity of the cardiovascular system and the continuous blood flow. Fibrinolysis serves as the completion step of homeostasis whereby unnecessary fibrin is removed from the vascular system. There are two basic steps that lead to fibrin degradation. The initial step is the activation of plasminogen to plasmin by several important protein/enzymes as tissue Plasminogen Activator (t-PA) and urokinase Plasminogen Activator (u-PA). In the second and final step, the active plasmin that is able to complex, with fibrin, specifically degrades the complexed fibrin into soluble fibrin degradation products (Hajjar, 2003).

Diabetes Mellitus (DM) is a chronic systemic metabolic disease that affects carbohydrates, fat and protein metabolism. It is complicated with increase deaths from coronary heart diseases and cerbro-vascular accidents. Type $2 \mathrm{DM}$ is basically characterized by the presence of peripheral insulin resistance which may be caused by either receptor defect or post receptor defect with an insulin secretory defect. Commonly type 2 DM is caused by overfeeding, obesity with depressed physical activity.
Endothelial dysfunction is characterized by a change of the actions of the endothelium toward reduced vasodilatation and a proinflammatory state. It is associated with most forms of cardiovascular disease, such as hypertension, coronary artery disease, chronic heart failure, peripheral artery disease, diabetes and chronic renal failure. Mechanisms that participate in the reduced vasodilatation in endothelial dysfunction include reduced nitric oxide generation, oxidative excess and reduced production of hyperpolarizing factor. Upregulation of adhesion molecules, generation of chemokines such as macrophage chemoattractant peptide-1 participate in the inflammatory response state (Verma and Anderson, 2002). Vasoactive peptides such as angiotensin II and endothelin-1; the accumulation of asymmetric dimethylarginine, an endogenous nitric oxide inhibitor; hypercholesterolemia; hyperhomocysteinemia; altered insulin signaling and hyperglycemia can contribute to these different mechanisms. In diabetes, the mechanism that may trigger endothelial dysfunction includes insulin resistance (as in type 2 diabetes). Decreased insulin sensitivity leads to induction of the two major pathways emerging from the insulin receptors; the first pathway is via phosphoinositide 3-kinase, phosphoinositidedependent kinase-1 and Akt/protein kinase B leading to marked depression of eNOS, whereas the second 
pathway is via mitogen activated protein kinases leading to mitogenic effects (Cusi et al., 2000; Montagnani et al., 2002; Osman et al., 2000; Federici et al., 2002). Moreover, hyperglycemia leads to Advanced Glycation End products (AGE), which were shown to quench NO and impair endothelial function (Zhang et al., 2003; Makita et al., 1991). Also, acute hyperglycemia attenuates endothelium-dependent vasodilatation in humans in vivo (Giugliano et al., 1997; Williams et al., 1998).

Endothelin was first described by Hickey et al. (1985) as a peptidergic endothelium-derived constricting factor. Three different endothelin peptides and are known, Endothelin-1,-2 and -3 (ET-1, ET-2 and ET-3, respectively). The most abundant endothelin peptide in circulation is endothelin-1. Under normal physiological conditions, ET-1 is not classified as a circulating hormone, but rather as an autocrine or paracrine factor at many sites of action in the body (Kedzierski and Yanagisawa, 2001). Elevated levels of ET-1 have been reported in numerous disease states including congestive heart failure, obesity and diabetes (Migdalis et al., 2000; Masaoka et al., 1989).

Hyperlipidemia in association with insulin resistance is common in patients with type 2 Diabetes Mellitus (DM) (Zavaroni et al., 1985; Garg and Grundy, 1990). Insulin resistance and the ensuing hyperinsulinemia are associated with hypertriglyceridemia and low serum High-Density Lipoprotein (HDL) cholesterol concentrations.

The lipoprotein abnormalities are related to the severity of the insulin resistance. A study that measured insulin sensitivity using a euglycemic clamp in patients with and without type 2 DM found that greater insulin resistance was associated with larger Very Low Density Lipoprotein (VLDL) particle size, smaller Low Density Lipoprotein (LDL) particle size and smaller HDL particle size (Garvey et al., 2003). Additionally, the number of VLDL, Intermediate Density Lipoprotein (IDL) and LDL particles increased with increasing insulin resistance. Hypertriglyceridemia results both from increased substrate availability (glucose and free fatty acids) and from decreased lipolysis of VLDL triglyceride.

The aim of the present study was to investigate the fibrinolytic activity changes in endothelial dysfunction induced by type 2 diabetes.

\section{MATERIALS AND METHODS}

Animals: Rats weighing 180-200 g were supplied from the animal house at College of Medicine at king Khalid University. The rats were divided into 10 rats/cage, the rats were housed in plastic cages at a temperature regulated $\left(22^{\circ} \mathrm{C}\right)$ and humidity $(55 \%)$ controlled room with a $12 \mathrm{~h}$ light/12 h dark cycle. and were allowed free access to normal rat chow (9\% fat, $20 \%$ protein, $53 \%$ starch and $5 \%$ fiber) plus water for 1 week. All studies were conducted in accordance with the National Institute of Health's Guide for the Care and Use of Laboratory Animals (National Institute of Health, 1996).

Experimental design: The animals were then divided randomly into two groups. Normal rats $(n=10)$ were fed normal rat chow and remained untreated for the duration of the study. Experimental rats $(\mathrm{n}=10)$ were fed a diet enriched in fat $(25 \%$ fat, $15 \%$ protein, $51 \%$ starch and 5\% fiber) (Jian et al., 1998). After 1 month on their respective diets, experimental rats were injected intraperitoneally with streptozotocin $\left(25 \mathrm{mg} \mathrm{kg}^{-1}\right.$ body weight) and normal rats were injected with vehicle (0.05 mol L ${ }^{-1}$ citric acid, $\left.\mathrm{pH} 4.5\right)$. Both the low dose of streptozotocin and the high-fat diet are essential elements of the model designed to induce type 2 diabetes with insulin resistance. After 1 month, rats were fasted overnight and given $20 \%$ glucose $\left(3 \mathrm{~g} \mathrm{~kg}^{-1}\right.$ body weight). Blood samples were taken from the tail vein to measure glucose and insulin levels at 2 and $12 \mathrm{~h}$ after glucose administration. Only rats with increased postprandial glucose $\left(>200 \mathrm{mg} \mathrm{dL}^{-1}\right)$ were considered diabetic.

Collection of blood plasma: the animals were subjected to overnight fasting and then were anaesthetized by ether and fresh blood samples were immediately withdrawn from the heart between 8:00 and 9:00 am. Blood samples were collected directly into tubes containing 3.8\% Trisodium Citrate (TSC) (1:9 TSC/blood, v/v), followed by centrifugation at $3000 \mathrm{rpm}$ for $15 \mathrm{~min}$ to obtain plasma which was frozen at $-20^{\circ} \mathrm{C}$ for further biochemical analysis.

Biochemical analysis: t-PA antigen, PAI-1 antigen and TDPs were determined by Enzyme Immunoassay (EIA) (IMULYSE) (Koopman et al., 1987; Koppert et al., 1987; 1988). Euglobulin Clot Lysis Time (ECLT) was measured using the method of Lidbury et al. (1990). The concentration of ET-1 in the plasma samples was determined by radioimmunoassay by use of commercially available kits (endothelin 1-21 speci®c125 assay system, Amersham International Plc., Buckinghamshire, UK.). The plasma was also analyzed for glucose, insulin and lipid profile. The HOMA -IR was calculated (Turner et al., 1993).

Statistical analysis: Data are expressed as the mean \pm SD. Student's t-test was used to determine if the difference observed among groups was significant. Statistical significance was considered at $\mathrm{p}<0.05$. 


\section{RESULTS}

Figure 1-4 showed that, the type 2 diabetic rats had a significant decrease in both t-PA from $2.1626 \pm 0.381$ $1.101 \pm 0.185 \mathrm{ng} \mathrm{mL}^{-1}$ and TDPs from $1.85 \pm 0.088$ $1.129 \pm 0.142 \mathrm{ng} \mathrm{mL}^{-1}$, with significant increase in PAI1 from $1.625 \pm 0.184-5.0345 \pm 0.748 \mathrm{mg} \mathrm{mL}^{-1}$. Moreover the ECLT was prolonged in diabetic rats from 63.72 $\pm 5.169-75.71 \pm 2.879$ min.

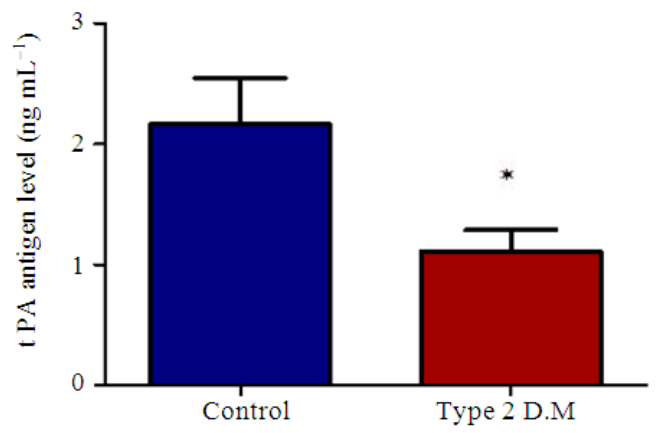

Fig. 1: t-PA antigen level in control and type 2 diabetic rats

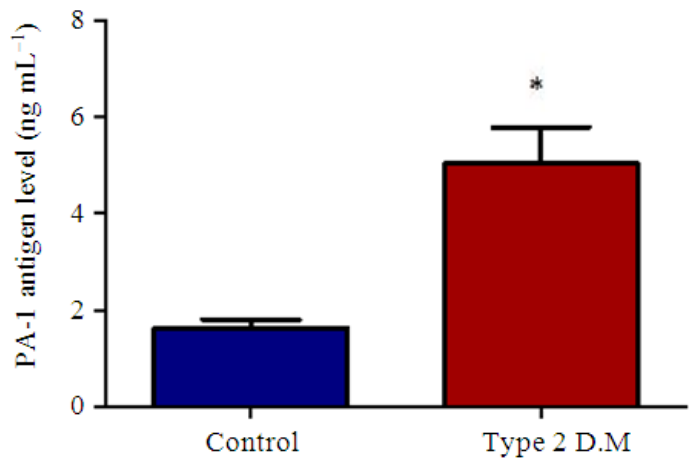

Fig. 2: PAI-1 antigen level in control and type 2 diabetic rats

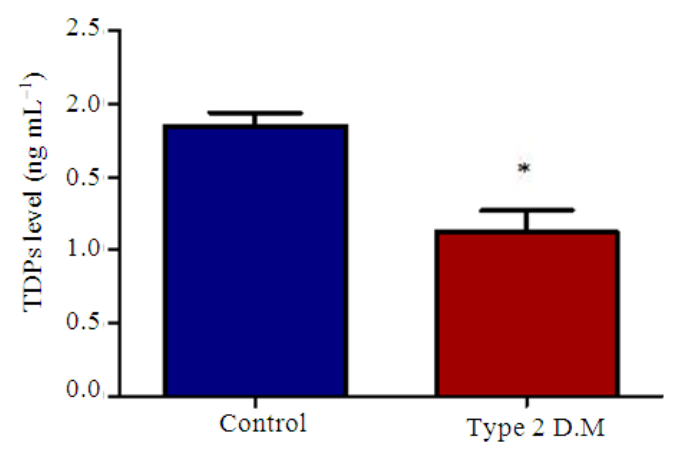

Fig. 3: TDPs level in control and type 2 diabetic rats
Figure 5 showed that the Plasma ET-1 level increased significantly in diabetic rats from $3.165 \pm 0.422-8.315 \pm 1.125 \mathrm{fmol} 100 \mu^{-1}$.

Table 1 showed that the diabetic rats had a significant increase in fasting glucose from $73 \pm 6.306$ $155.4 \pm 13.68 \mathrm{mg} \mathrm{dL}^{-1}$, fasting insulin level from3.69 \pm 0.356 to $10.637 \pm 1.636 \mu \mathrm{U} \mathrm{mL}^{-1}$ and postprandial glucose from $92.3 \pm 7.103$ to $282.8 \pm 21.632 \mathrm{mg} \mathrm{dL}^{-1}$ when compared to control group. Also HOMA-IR was significantly increased from $0.665 \pm 0.086$ to $4.101 \pm 0.818$, indicating the presence of insulin resistance.

The lipid profile in Table 2 showed significant increase in cholesterol from $82.2 \pm 7.983$ to105.8 $\pm 9.040 \mathrm{mg} \mathrm{dL}^{-1}$, triglycerides from $84.4 \pm 3.949$ to $107.9 \pm 6.505 \mathrm{mg} \mathrm{dL} \mathrm{dL}^{-1}$ and LDLcholesterol $23.6 \pm 3.893$ to $40.3 \pm 5.417 \mathrm{mg} \mathrm{dL}^{-1}$ with significant decrease in HDL-cholesterol from $43.1 \pm 3.60$ to $27.7 \pm 3.128 \mathrm{mg} \mathrm{dL}^{-1}$ in the diabetic rats as compared to the control group.

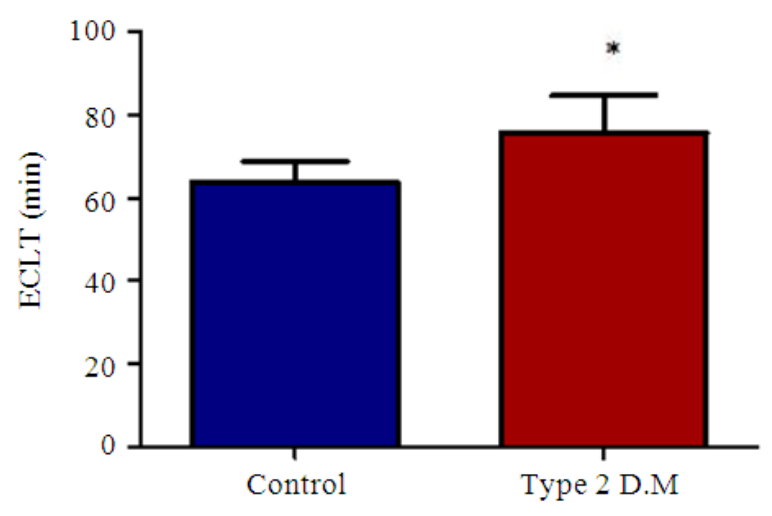

Fig. 4: ECLT in control and type 2 diabetic rats

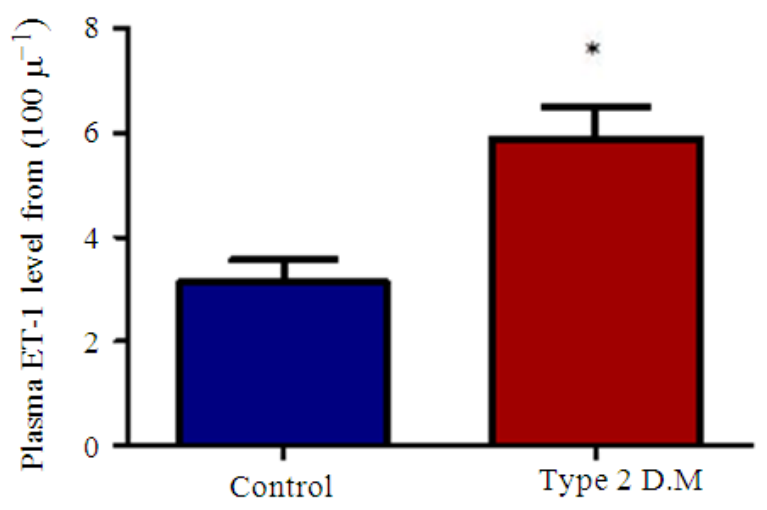

Fig. 5: ET-1 level in control and type 2 diabetic rats 
Am. J. Biochem. \& Biotech., 6 (2): 103-110, 2010

Table 1: Fasting glucose, insulin, post-prandial glucose levels in the plasma and HOMA-IR calculations for the control and the experimental groups of rats

\begin{tabular}{lccc}
\hline & Fasting GLU & PP glucose & Insulin \\
\hline Control group & $73.0 \pm 06.306$ & $92.3 \pm 7.103$ & $3.690 \pm 0.356$ \\
Type 2 diabetic rats & $155.4 \pm 13.680^{*}$ & $282.8 \pm 21.632^{*}$ & $0.665 \pm 0.086$ \\
\hline ValuO-IR & $4.101 \pm 0.818^{*}$ \\
\hline
\end{tabular}

Values are given as mean \pm SD for groups of ten rats each; Values are statistically significant at $\mathrm{p}^{*}<0.05$ as compared to control group

Table 2: Cholesterol, triglycerides, LDL and HDL-cholesterol levels in the plasma of the control and the experimental groups of rats

\begin{tabular}{|c|c|c|c|c|}
\hline & Cholesterol & Triglycerides & LDL & HDL \\
\hline Control group & $82.2 \pm 7.983$ & $84.4 \pm 3.949$ & $23.6 \pm 3.893$ & $43.1 \pm 3.60$ \\
\hline Type 2 diabetic rats & $105.8 \pm 9.040^{*}$ & $107.9 \pm 6.505^{*}$ & $40.3 \pm 5.417 *$ & $27.7 \pm 3.128 *$ \\
\hline
\end{tabular}

\section{DISCUSSION}

The present study was designated to study the effect of endothelial dysfunction induced by type $2 \mathrm{DM}$ on the fibrinolytic activity in rats. The endothelial dysfunction in type $2 \mathrm{DM}$ is caused by different mechanisms as described previously mainly due to insulin resistance and the uncontrolled hyperglycemia. The endothelial dysfunction is defined as decrease in the endothelial release of the vasodilator substances, with increased synthesis and expression of the vasoconstrictor substances like ET-1 with increasing the pro-inflammatory substances than the antiinflammatory substances. The biological markers of endothelial dysfunction include von-Willibrand factor, E-selectin and endothelin-1, so in the present study ekdothelin-1 was measured to prove the presence of endothelial dysfunction. In agreement to our data, ET-1 was significantly increased in the diabetic rats concluding the presence of endothelial dysfunction as compared with the control group (Fig. 5) which is caused possibly by the hyperglycemia, hyperinsulinemia and altered insulin signaling. In agreement to our data, plasma levels of ET-1 are elevated in diabetes mellitus (Kakizawa et al., 2004). The possible factors which increase ET-1 expression include leptin, insulin and TNF- $\alpha$. Levels of these factors are elevated in obesity and diabetes and their effects on ET-1 production have investigated by several laboratories. Interestingly, leptin increased ET-1 mRNA and protein release from the human umbilical vein endothelial cells in a dose and time dependent manner (Quehenberger et al., 2002). In the presence of $\gamma$ interferon, TNF- $\alpha$ increased ET- 1 expression and release from human vascular smooth muscle cells (Woods et al., 1999). Glucose induced insulin secretion from pancreatic B-cells resulted in a moderate but significant rise in circulating ET-1 levels (Ferri et al., 1996).

Moreover, elevated levels of ET-1 in obese and diabetic patients may contribute to endothelial dysfunction as well as impaired insulin signaling in these patients. Studies suggest that ET-1 mediated vasoconstriction is increased in insulin resistant states such as obesity and diabetes. Ishibashi et al. (2001) demonstrated that chronic exposure to ET-1 led to decrease insulin and ET-1 stimulated glucose uptake.

From our data, the significant increase of ET-1 in the diabetic rats could contribute in inhibiting the fibrinolytic activity either by decreasing t-PA or increasing PAI-1. ET-1 seems to be an important modulator of smooth muscle cell function. It is a potent vasoconstrictor peptide released from endothelial cells which also regulates smooth muscle cell proliferation. Thus, it is thought to be implicated in several pathophysiological conditions of the cardiovascular system associated with endothelial cell damage and/or smooth muscle cell proliferation such as myocardial infarction and atherosclerosis. On the other hand, these pathological states have also been shown to be associated with elevated PAI-l activity in blood and the expression of PAI-1 in atherosclerotic.

ET-1 and ET-3 seem to be implicated in the regulation of the fibrinolytic system of increasing the expression of PAI-1 and simultaneously decreasing the expression of t-PA in cultured smooth muscle cells via activation of endothelin-B receptors. Changes in the fibrinolytic system of smooth muscle cells correlate with proliferation and migration of these cells. ET-1 which then would act in a paracrine way to activate the underlying smooth muscle cells Such activation of the smooth muscle cells would not only result in vasoconstriction and smooth muscle cell proliferation through activation of endothelin-A receptors, but might also contribute to an antifibrinolytic and antiproteolytic environment. An autocrine role for ET-1 in this latter process has been suggested because ET-1 has been shown to decrease basal and thrombin-stimulated t-PA release from cultured endothelial cells. One could also speculate on anautocrine/paracrine effect in which ET-1 in smooth muscle cells and endothelial cells, would contribute to the upregulation of PAI-1 expression in these cells (Kaji et al., 1992). 
Plasminogen is synthesized as a single chain molecule which is cleaved by t-PA into two chain disulfide linked plasmin. The t-PA is a serine protease which converts the proenzyme plasminogen to plasmin, a fibrinolytic enzyme. This enzyme plays a role in cell migration and tissue remodling. Increased enzymatic activity causes hyperfibrinolysis, which manifests as excessive bleeding; while decreased activity leads to hypofibrinolysis which can result in thrombosis or embolism (Levin et al., 1998).

PAI-1 is the principal inhibitor of tissue Plasminogen Activator (t-PA) and urokinase (u-PA), the activators of plasminogen and hence fibrinolysis (the physiological breakdown of blood clots). It is a serine protease inhibitor (serpin) which is secreted by different cell types including the endothelium, vascular smooth muscle cells, hepatocytes, platelets and the adipocyte. The main role of PAI-1 is probably to limit the fibrinolytic activity of a haemostatic plug. The increase in the plasma level of PAI-1 is associated with increased clearance of t-PA. Complexes between tissuetype Plasminogen Activator (t-PA) and its rapidly acting inhibitor Plasminogen Activator Inhibitor type 1 (PAI-1) are bound, internalized and degraded by HepG2 cells. The mechanism involves endocytosis mediated by a specific high-affinity receptor (Owensby et al., 1989). PAI-1 is the major fibrinolytic determinant that strongly influences both basal and exercise-induced fibrinolytic activity (Hamsten et al., 1985).

The data obtained from this study concluded that the fibrinolytic activity was inhibited in the diabetic rats as detected by the significant decrease in t-PA antigen level with the significant increase in the PAI-1 antigen level. Also, the ECLT was significantly prolonged in the diabetic group versus the control and the TDPs of fibrinogen and fibrin was significantly reduced.

Several possible mechanisms describe the prothrombotic state in the diabetics. The first mechanism of this prothrombotic condition is the endothelial dysfunction induced by the hyperglycemia and the insulin resistances seen in type 2 D.M. Patients with diabetes invariably show an impairment of endothelium-dependent vasodilation. This is partly due to the frequent association of the disease with other cardiovascular risk factors, including hypertension, obesity and dyslipidemia. Moreover diabetic as well as obese patients usually consume a high-calorie diet rich in macronutrients that per se is able to induce vascular abnormalities. Indeed, protein, lipid (Mohanty et al., 2002) and glucose (Mohanty et al., 2000) loads are associated with a marked production in ROS and highfat meals are associated with an impaired endothelialdependent vasodilation (Vogel et al., 1997). A crucial negative effect is particularly attributable to high levels of circulating free fatty acids, which are able to induce ROS production and impair endothelial function (Tripathy et al., 2003). Mechanisms of endothelial damage in diabetes, independently from other cardiovascular risk factors, include insulin resistance, hyperglycemia and low-grade systemic inflammation (Calles-Escandon and Cipolla, 2001).

Endothelial dysfunction is characterized by increased the prothrombotic markers like PAI-1, von Willibrand factor and tissue factor with depression of the fibrinolytic parameters particularly t-PA. The inhibition in fibrinolysis in endothelial dysfunction, this was reported by several previous studies.

Other possible mechanisms of inhibition of the fibrinolytic activity in diabetic rats include insulin resistance present in the diabetic rats which leads to induction of fatty liver and by the accumulation of white adipose tissue specially, in the central region. This is in agreement with Bastard et al. (2000) and Jackson et al. (2005) who found that white adipose tissue is the main tissue source of elevated plasma PAI1 in obesity, with a major participation from visceral fat.

Also, Esposito et al. (2002) and Lopez-Garcia et al. (2005) found that insulin resistance and endothelial dysfunction detected in obesity is associated with decrease t-PA secretion from the endothelial cells as a result from endothelial dysfunction.

TNF- $\alpha$, a pro-inflammatory cytokine that is chronically elevated in adipose tissue in obese and insulin resistance states like type 2 D.M. and that is produced by adipose tissue, stimulates the production of PAI-1 by adipose tissue in vitro, ex vivo in human adipose tissue explants and in vivo in mice. Hence, adipose tissue itself may regulate PAI-1 expression by paracrine and autocrine effects. Moreover, TNF-aneutralizing antibodies blocked induction of PAI-1 production. TNF- $\alpha$ may also influence PAI-1 production by modulating the TGF- $\beta$ pathway. The TNF- $\alpha$ and TGF- $\beta$ pathways are interrelated, as deletion of $\mathrm{TNF}-\alpha$ receptors resulted in a major decrease of TGF- $\beta$. The multifunctional cytokine TGF$\beta$ is capable of increasing plasma PAI-1 activity and PAI-1 expression and it up-regulates PAI-1 production specifically in adipose tissue. Furthermore, analogous to TNF $\alpha$, TGF- $\beta$ mRNA expression is increased in adipose tissue in obesity; thus, TGF- $\beta$ may locally regulate PAI-1 expression. In human cultured isolated adipocytes substantial increases in PAI-1 production were found after stimulation with TGF- $\beta$ (Loskutoff and Samad, 1998; Samad et al., 1999). 
Hypetriglyceridemia which is one of the most important features of insulin resistance detected in type $2 \mathrm{DM}$ is associated with inhibition of the fibrinolytic activity due to increased secretion of PAI1 (Oishi et al., 2006). High levels of VLDL stimulate increased PAI-1 synthesis and secretion by cultured human endothelial cells. This transcriptional regulation of PAI-1 expression by VLDL has been shown to be genotype-specific. Also, Tabengwa et al. (2000) suggested that the repression of t-PA gene expression by VLDL may contribute to the impaired fibrinolysis.

Several mechanisms for PAI-1 overexpression in adipose tissue have been proposed. Evidence from mouse studies, using lean insulin sensitive and obese insulin resistant mice, indicated that hyperinsulinemia leads to increased PAI-1 plasma levels and increased PAI-1 gene expression in adipose tissue, which confirmed the role of adipose tissue in PAI-1 induction. It was shown that the PAI-1 gene remains sensitive to the action of insulin in the presence of insulin resistance, because several insulin signaling pathways remain functional in insulin resistance. Apparently, some consequences of obesity such as up-regulation of PAI-1 are not due to insulin resistance but rather caused by compensatory hyperinsulinemia. In human adipocytes and human adipose tissue explants, it was also demonstrated that insulin induces PAI-1 production in adipocytes. In human adipose tissue explants, however, insulin-stimulated PAI-1 production was restricted to adipocytes, indicating that mainly the adipocyte fraction of adipose tissue is sensitive to increased insulin levels. The increased PAI-1 synthesis by visceral fat compared to subcutaneous fat may be explained by the greater and more rapid response of visceral adipocytes to insulin than the response of subcutaneous adipocytes (Shoelson et al., 2006).

Also, one of the possible mechanisms of hypofibrinolysis is the hyperglycemia and hyperinsulinemia detected in diabetic rats. These was also concluded by Pandolfi et al. (2001) who concluded that acute hyperglycemia and acute hyperinsulinemia can decrease plasma fibrinolytic potential and that this is due to increased plasma PAI-1 and decreased free tPA activities.

\section{CONCLUSION}

From our data, we conclude that endothelial dysfunction caused by type 2 diabetes mellitus is associated with a prothrombotic state characterized by inhibition of the fibrinolytic activity that may increase the incidence of thrombo-embolic accidents.

\section{ACKNOWLEDGEMENT}

The author would like to introduce deep thanks and great appreciation to Mr. Mahmoud Al-Khateeb from physiology department, college of medicine, king Khalid University for his great contribution in the experimental designing and performing the biochemical measurements.

\section{REFERENCES}

Bastard, J.P., H. Vidal, C. Jarde, E. Bruckert and D. Robin et al., 2000. Subcutaneous adipose tissue expression of plasminogen activator inhibitor-1 gene during very low calorie diet in obese subjects. Int. J. Obes. Relat. Metab. Disord., 24: 70-74. PMID: 10702753

Calles-Escandon, J. and M. Cipolla, 2001. Diabetes and endothelial dysfunction: A clinical perspective. Endocr. Rev., 22: 36-52. PMID: 11159815

Cusi, K., K. Maezono, A. Osman, M. Pendergrass and M.E. Patti et al., 2000. Insulin resistance differentially affects the PI 3-kinase- and MAP kinase-mediated signaling in human muscle. J. Clin. Invest., 105: 311-320. PMID: 10675357

Esposito, K., G. Nicoletti and D. Giugiliano, 2002. Obesity, cytokines and endothelial dysfunction: A link for the raised cardiovascular risk associated with visceral obesity. J. Endocrinol. Invest., 25: 646-649. PMID: 12150343

Federici, M., R. Menghini, A. Mauriello, M.L. Hribal and F. Ferrelli et al., 2002. Insulin-dependent activation of endothelial nitric oxide synthase is impaired by O-linked glycosylation modification of signaling proteins in human coronary endothelial cells. Circulation, 106: 466-472. PMID: 12135947

Ferri, C., C. Bellini, G. Desideri, G. De Mattia and A. Santucci, 1996. Endogenous insulin modulates circulating endothelin-1 concentrations in humans. Diabetes Care, 19: 504-506. PMID: 8732718

Garg, A. and S.M. Grundy, 1990 Nicotinic acid as therapy for dyslipidemia in non-insulin-dependent diabetes mellitus. J. Am. Med. Assoc., 264: 723-726. PMID: 2374275

Garvey, W.T., S. Kwon, D. Zheng, S. Shaughnessy and P. Wallace et al., 2003. Effects of insulin resistance and type 2 diabetes on lipoprotein subclass particle size and concentration determined by nuclear magnetic resonance. Diabetes, 52: 453-462. PMID: 12540621

Giugliano, D., R. Marfella, L. Coppola, G. Verrazzo and R. Acampora et al., 1997. Vascular effects of acute hyperglycemia in humans are reversed by L-arginine. Evidence for reduced availability of nitric oxide during hyperglycemia. Circulation, 95: 1783-1790. PMID: 9107164 
Hajjar, K.A., 2003. The Molecular Basis of Fibrinolysis. In: Hematology of Infancy and Childhood. Nathan, D.G. S.H. Orkin, D. Ginsburg and A.T. Look (Eds.). WB Saunders, Philadelphia, pp: 1497.

Hamsten, A., B. Wiman, F.U. De and M. Blomback, 1985. Increased plasma levels of a rapid inhibitor of tissue plasminogen activator in young survivors of myocardial infarction. N. Engl. J. Med., 313: 1557-1563. PMID: 3934538

Hickey, K.A., G. Rubanyi, R.J. Paul and R.F. Highsmith, 1985. Characterization of a coronary vasoconstrictor produced by cultured endothelial cells. Am. J. Physiol., 248: C550-C556. PMID: 3993773

Ishibashi, K.I., T. Imamura, P.M. Sharma, J. Huang and S. Ugi et al., 2001. Chronic endothelin-1 treatment leads to heterologous desensitization of insulin signaling in 3T3-L1 adipocytes. J. Clin. Invest., 107: 1193-1202. DOI: 10.1172/JCI11753

Jackson, M.B., Y.O. Suzette and A.S. Rexford, 2005. The endocrine role of adipose tissue: Focus on adiponectin and resistin. Current opinion in endocrinology and diabetes. The endocrine role of adipose tissue: Focus on adiponectin and resistin. Endovrinol. Diabetes, 12: 163-170.

Jian, L., Q. Josephine, T. Joyce, K.H. Christina and S. Cynthia et al., 1998. Nongenetic mouse models of non-insulin dependent diabetes mellitus. Metabolism, 47: 663-668. DOI: 10.1016/S00260495(98)90027-0

Kaji, T., C. Yamamoto, M. Sakamoto and R. Koizumi, 1992. Endothelin modulation of tissue plasminogen activator release from human vascular endothelial cells in culture. Blood Coagul Fibrinol., 3: 5-10. PMID: 1377954

Kakizawa, H., M. Itoh, Y. Itoh, S. Mamura and Y. Ishiwata et al., 2004. The relationship between glycemic control and plasma vascular endothelial growth factor and endothelin-1 concentration in diabetic patients. Metabolism, 53: 550-555. PMID: 15131756

Kedzierski, R.M. and M. Yanagisawa, 2001. Endothelin system: The double-edged sword in health and disease. Annu. Rev. Pharmacol. Toxicol., 41: 851-876. PMID: 11264479

Koopman, J., F. Haverkate, P. Koppert, W. Nieuwenhuizen and E.J. Brommer et al., 1987. New enzyme immunoassay of fibrin-fibrinogen degradation products in plasma using a monoclonal antibody. J. Lab. Clin. Med., 109: 75-84. PMID: 3540164

Koppert, P.W., E. Hoegee-de Nobel and W. Nieuwenhuizen, 1988. A monoclonal antibody-based enzyme immunoassay for fibrin degradation products in plasma. Thromb. Haemost., 59: 310-315. PMID: 3133813
Koppert, P.W., W. Kuipers, B. Hoegee-de Nobel, E.J.P. Brommer and J. Koopman et al., 1987. A quantitative enzyme immunoassay for primary fibrinogenolysis products in plasma. Thromb. Haemost., 57: 25-28. PMID: 7937785

Levin, E.G., K.G. Osborn and W.D. Schleuning, 1998. Vessel-specific gene expression in the lung: Tissue plasminogen activator is limited to bronchial arteries and pulmonary vessels of discrete size. Chest, 114: 68S-68S. PMID: 9676639

Lidbury, P.S., R. Korbut and J.R. Vane, 1990. Sodium nitroprusside modulates the fibrinolytic system in the rabbit. Br. J. Pharmacol., 101: 527-530. PMID: 2127549

Lopez-Garcia, E., M.B. Schulze, J.B. Meigs, J.E. Manson and N. Rifai et al., 2005. Consumption of trans fatty acids is related to plasma biomarkers of inflammation and endothelial dysfunction. J. Nutrit., 135: 562-566. PMID: 15735094

Loskutoff, D.J. and F. Samad, 1998. The adipocyte and hemostatic balance in obesity: studies of PAI-1. Arterioscler. Thromb. Vasc. Biol., 18: 1-6. PMID: 9445248

Makita, Z., S. Radoff, E.J. Rayfield, Z. Yang and E. Skolnik et al., 1991. Advanced glycosylation end products in patients with diabetic nephropathy. N. Engl. J. Med., 325: 836-842. http://www.jci.org/articles/view/116696/files/pdf

Masaoka, H., R. Suzuki, Y. Hirata, T. Emori and F. Marumo, 1989. Raised plasma endothelin in aneurysmal subarachnoid haemorrhage. Lancet, 2: 1402. PMID: 8301307

Migdalis, I.N., K. Kalogeropoulou, K.D. Karmaniolas, N. Varvarigos and P. Cordopatis, 2000. Plasma level of endothelin and early carotid atherosclerosis in diabetic patients. Res. Commun. Mol. Pathol. Pharmacol., 108: 15-25. PMID: 11758970

Mohanty, P., W. Hamouda, R. Garg, A. Aljada and A. Ghanim et al., 2000. Glucose challenge stimulates Reactive Oxygen Species (ROS) generation by leucocytes. J. Clin. Endocrinol. Metab., 85: 2970-2973. PMID: 10946914

Mohanty, P., H. Ghanim, W. Hamouda, A. Aljada, R. Garg and P. Dandona, 2002. Both lipid and protein intakes stimulate increased generation of reactive oxygen species by polymorphonuclear leukocytes and mononuclear cells. Am. J. Clin. Nutr., 75: 767-772. PMID: 11916766

Montagnani, M., L.C. Ravichandran, H. Chen, D.L. Esposito and M.J. Quon, 2002. Insulin receptor substrate-1 and phosphoinositidedependent kinase-1 are required for insulinstimulated production of nitric oxide in endothelial cells. Mol. Endocrinol., 16: 1931-1942. http://mend.endojournals.org/cgi/content/full/16/8/1931 
National Institute of Health, 1996. Guide for the care and use of laboratory animals. National Academy Press. http://oacu.od.nih.gov/regs/guide/guide.pdf

Oishi, K., N. Ohkura, M. Wakabayashi, H. Shirai and K. Sato et al., 2006. Clock is involved in obesityinduced disordered fibrinolysis in ob/ob mice by regulating PAI-1 gene expression. Thromb. Haemost., 4: 1774-1780. DOI: 10.1097/MOL.0b013e32814e6d29

Osman, A.A., M. Pendergrass, J. Koval, K. Maezono and K. Cusi et al., 2000. Regulation of MAP kinase pathway activity in vivo in human skeletal muscle. Am. J. Physiol. Endocrinol. Metab., 278: 992-999. http://ajpendo.physiology.org/cgi/content/full/278/ 6/E992

Owensby, D.A., P.A. Morton and A.L. Schwartz, 1989. Interactions between tissue-type plasminogen activator and extracellular matrix-associated plasminogen activator inhibitor type 1 in the human hepatoma cell line HepG2. J. Biol. Chem., 264: 18180-18187. http://www.jbc.org/content/264/30/18180.short

Pandolfi, A., A. Giaccari, C. Cilli, M.M. Alberta and L. Morviducci et al., 2001. Acute hyperglycemia and acute hyperinsulinemia decrease plasma fibrinolytic activity and increase plasminogen activator inhibitor type 1 in the rat. Acta Diabetologica, 38.71-76. DOI: 10.1007/s005920170016

Quehenberger, P., M. Exner, R. Sunder-Plassmann, K. Ruzicka and C. Bieglmayer et al., 2002. Leptin induces endothelin-1 in endothelial cells in vitro. Circ Res., 90: 711-718. PMID: 11934840

Samad, F., K.T. Uysal, S.M. Wiesbrock, M. Pandey and G.S. Hotamisligil et al., 1999. Tumor necrosis factor alpha is a key component in the obesitylinked elevation of plasminogen activator inhibitor. Proc. Natl. Acad. Sci. USA., 96: 6902-6907. http://endo.endojournals.org/cgi/content/abstract/1 39/12/4832

Shoelson, S.E., J. Lee and A.B. Goldfine, 2006. Inflammation and insulin resistance. J. Clin. Invest., 116: 1793-1801. http://www.jci.org/articles/view/29069

Tabengwa, E.M., R.L. Benza, H.E. Grenett and F.M. Booyse, 2000. Activator promoter in cultured human endothelial cells transcription through cisrepressive region(s) in the tissue plasminogen hypertriglyceridemic VLDL downregulates tissue plasminogen activator gene. Arterioscler. Thromb. Vasc. Biol., 20: 1675-1681. PMID: 10845888
Tripathy, D., P. Mohanty, S. Dhindsa, T. Syed and H. Ghanim et al., 2003. Elevation of free fatty acids induces inflammation and impairs vascular reactivity in healthy subjects. Diabetes, 52: 2882-2887. PMID: 14633847

Turner, R.C., J.C. Levy, A.S. Rudesnki, M. Hammersley and R. Page, 1993. Measurement of Insulin Resistance and $\beta$-Cell Function: The HOMA and CIGMA Approach. In: Current Topics in Diabetes Research, Belfiore, F., R.N. Bergman and G.M. Molinatti (Eds.). Basel, Karger, 12: 66-75.

Verma, S. and T.J. Anderson, 2002. Fundamentals of endothelial function for the clinical cardiologist. Circulation, 105: 546-549. PMID: 11827916

Vogel, R.A., M.C. Corretti and G.D. Plotnick, 1997. Effect of a single high-fat meal on endothelial function in healthy subjects. Am. J. Cardiol., 79: 350-354. PMID: 9036757

Williams, S.B., A.B. Goldfine, F.K. Timimi, H.H. Ting and M.A. Roddy et al., 1998. Acute hyperglycemia attenuates endothelium-dependent vasodilation in humans in vivo. Circulation, 97: 1695-1701. PMID: 9591763

Woods, M., J.A. Mitchell, E.G. Wood, S. Barker and N.R. Walcot et al., 1999. Endothelin-1 is induced by cytokines in human vascular smooth muscle cells: evidence for intracellular endothelinconverting enzyme. Mol. Pharmacol., 55: 902-909. PMID: 10220569

Zavaroni, I., E., Dall'Aglio, O. Alpi, F. Bruschi and E. Bonora et al., 1985. Evidence for an independent relationship between plasma insulin and concentration of high density lipoprotein cholesterol and triglyceride. Atherosclerosis, 55: 259-266. PMID: 3893447

Zhang, L., A. Zalewski, Y. Liu, T. Mazurek and S. Cowan et al., 2003. Diabetes-induced oxidative stress and low-grade inflammation in porcine coronary arteries. Circulation, 108: 472-478. PMID: 12860917 